\title{
AN ELDERLY THYROTOXIC PATIENT PRESENTED WITH ANOREXIA COMPLICATED TO CARDIAC ARREST
}

\author{
FAZLE RABBI CHOWDHURY ${ }^{1}$, ABDUL MUMITH RUHAN ${ }^{2}$, NAZIA HASSAN ${ }^{3}$, MD. MUJIBUR RAHMAN ${ }^{4}$, \\ QUAZI TARIKUL ISLAM ${ }^{5}$, H.A.M.NAZMUL AHASAN6
}

\begin{abstract}
:
Hyperthyroidism is a common endocrine disorder. Earlier this disorder had been found in the young to middle age group, whereas it is now well recognized in elderly. Young patients generally presented with typical symptoms and signs where it can be diagnosed easily. But in elderly the presentation is varied and often atypical. Among the older adults the diagnosis is often overlooked or missed as many patients presented with uncommon symptoms. Here an elderly presented with anorexia that subsequently developed thyrotoxic crisis followed by cardiac arrest (due to hypokalaemia) and multi-organ dysfunction syndrome in the background of urinary tract infection.
\end{abstract}

Keywords: Hypertension, Thyrotoxic crisis, Anorexia

\section{Introduction:}

Hyperthyroidism is a common endocrine disorder with prevalence varying on different ethnic group, geographic area and criteria for diagnosis. The prevalence of hyperthyroidism ranges from $0.5-2.3 \%{ }^{1}$ Individuals over the age of 60 years constitute 10$15 \%$ of the disease load. ${ }^{2}$ In the past this disorder had been found in the young to middle age group, whereas it is now well recognized in elderly population. In the elderly groups, the studies were mainly done in Europe with the prevalence of 10-20\% and a few studies were done in Asia where it was $6.98 \% .{ }^{1}$ Hyperthyroidism can be easily diagnosed in young patients because of the typical symptoms and signs. But in elderly the presentation is varied and causes higher mortality and morbidity due to delayed diagnosis. ${ }^{1}$ In this write-up an uncommon presentation of hyperthyroidism has been described which increased the patient's morbidity due to delayed diagnosis.

\section{Case report:}

A 64 years retired government officer, known hypertensive for 25 years, started to experience anorexia and malaise for three and half months. He also experienced occasional rise of temperature with a highest peak of $100^{\circ} \mathrm{F}$ which subsided without medication. He was found mildly anaemic (Hb-10.0 $\mathrm{g} / \mathrm{dL}$ ) with high ESR (85 $\mathrm{mm}$ in 1st hour) and raised blood pressure (160/85 $\mathrm{mm}$ of $\mathrm{Hg}$ ). Though his BP was always controlled, but he noticed that over the last three and half months his systolic pressure remained high and it required increase of drugs and dose for control. His anorexia was increasing over time and became severe. The patient did not experience any visible blood loss. But still to evaluate the cause of anemia and anorexia upper GI endoscopy, colonoscopy and $\mathrm{CT}$ scan of abdomen were done which were inconclusive. During the course of illness suddenly he developed high grade fever with a peak of $103^{\circ} \mathrm{F}$. At the day of admission he became restless and disoriented. His admission BP was 90/60 mm of $\mathrm{Hg}$ with bilateral basal crepitation. ECG showed ST depression and flattening of $\mathrm{T}$ wave. Within one and half an hour of admission he developed sudden cardiac arrest. Emergency resuscitation was given and he was shifted into Intensive Care Unit (ICU) under artificial ventilation. Detailed laboratory investigation was done which revealed neutrophilic leucocytosis $(17,000 / \mathrm{cu} \mathrm{mm}$ with neutrophil $87 \%)$, hypokalaemia $(1.5 \mathrm{mmol} / \mathrm{L})$, high blood urea $(65.0 \mathrm{mg} / \mathrm{dL})$ and $\mathrm{S}$. Creatinine $(3.5 \mathrm{mg} / \mathrm{dL})$. Liver function test showed

1. Registrar, Department of Medicine, Sylhet M.A.G.Osmani Medical College, Sylhet, Bangladesh

2. Medical Officer, Gowainghat Upazilla Health Complex, Sylhet, Bangladesh.

3. Post Graduate Trainee, Department of Gastroenterology, Sylhet M.A.G.Osmani Medical College, Sylhet, Bangladesh.

4. Professor, Department of Medicine, ShaheedSohrawardy Medical College, Dhaka, Bangladesh.

5. Professor, Department of Medicine, Popular Medical College, Dhaka, Bangladesh.

6. Professor and Head, Department of Medicine, Dhaka Medical College, Dhaka, Bangladesh.

Correspondence to: Dr. Fazle Rabbi Chowdhury, Atlantic Topaz, Flat-3/B, 262, Elephant Road, Dhaka- 1205, Dhaka, Bangladesh, Email: mastershakil@hotmail.com

Bangladesh J Medicine 2014; 25 : 29-30 
high S. Bilirubin (2.07 mg/dL) and SGPT (2148 U/ L).All viral markers were negative along with ICT for malaria and febrile antigen test. Routine urine examination showed plenty of pus cell and 10-15/ HPF RBC. Coagulation profile showed increased Prothrombin Time (20 sec) and APTT (41 sec) along with raised FDP - >20 $\mu \mathrm{g} / \mathrm{ml}$ (Normal range: $<5$ ) and D-Dimer - $1000.0 \mathrm{ng} / \mathrm{ml}$ (Normal range: <250). Troponin-I was $9.27 \mathrm{ng} / \mathrm{ml}$ which was reduced to 1.59 $\mathrm{ng} / \mathrm{ml}$ on the next day.

Based on clinical features and laboratory reports he was diagnosed as a case of septicaemia due to Urinary Tract Infection (UTI) followed by multiorgan dysfunction syndrome (MODS) notably cardiac failure, hepatic and renal impairment and Disseminated Intravascular Coagulation (DIC). He was managed by giving all supportive treatment. On the $4^{\text {th }}$ day of ICU stay he became afebrile and recovered from cardiac arrest; but developed atrial fibrillation. His investigations were reviewed and showed gradual normalization of all previous findings but very abnormal thyroid function test. His free $\mathrm{T}_{3}$ was $37 \mathrm{p}$ $\mathrm{mol} / 1$, free $\mathrm{T}_{4}$ was $41 \mathrm{p} \mathrm{mol} / 1$ and TSH was $<0.003$ $\mathrm{iU} / \mathrm{ml}$. On query the patient mentioned that he was diagnosed as subclinical hyperthyroid 3 years back, but did not proceed for further evaluation or management. He was finally now diagnosed as a case of Thyrotoxic crisis. It was crisis on previous subclinical hyperthyroidism precipitated by UTI along with MODS. Patient was treated with carbimazole, Lugol's iodine and propranolol. On the $10^{\text {th }}$ day he was discharged with significant clinical and biochemical improvement. The patient is now on regular follow up with resolution of all complaint.

\section{Discussion:}

Hyperthyroidism is a treatable condition, but can cause life threatening complication if not treated in a timely manner. ${ }^{3}$ This elderly gentleman presented with prolonged anorexia which is an unusual feature of hyperthyroidism. Anorexia in an elderly anaemic person clinches us towards the suspicion of malignancy. This is why detailed investigation was done pointing that everything was normal. In the course of illness the patient developed UTI precipitating subclinical hyperthyroidism into thyrotoxicosis complicated by hypokalaemia with resultant cardiac arrest. UTI was also complicated by septicaemia. Cardiac arrest, DIC, hepatic and renal involvement in combination with septicaemia led to MODS. Troponin-I was raised immediately after CPR which came down to normal on the next day indicating the absence of permanent myocardial damage. After receiving the treatment of thyrotoxic crisis within few days all the symptoms were relieved including anorexia.

Here the primary pathology was hyperthyroidism which was hidden due to unusual presentation i,e, anorexia. Studies in various population revealed that presentation of hyperthyroidism in elderly is often atypical. ${ }^{4}$ Among the older adults the diagnosis isoften overlooked or missed as many patients presented with atypical symptoms. ${ }^{5,6}$ Few authors described that older adults can present with weight loss and anorexia. 7,8 The role of GI tract in the physiology of thyroid hormone might be the reason for that. The vertebrate thyroid gland has its embryogenic origin in the primitive foregut. That's why salivary gland and gastric mucosa have the ability to concentrate iodine. Moreover, normal physiology of thyroid hormone is dependent upon hepatic storage, metabolism and release of thyroid hormone as well as gut absorption of iodine and thyroxine. ${ }^{9}$

This report demonstrates an uncommon presentation in which hyperthyroidism was masked by protracted GI symptom. Diagnosis depends upon a high index of clinical suspicion and willingness to seek information by appropriate laboratory test. This also emphasizes the importance of including thyroid function test in the evaluation of patients with prolonged unexplained GI symptom specially in elderly.

\section{References:}

1. Limpawattana $\mathrm{P}, \quad$ Sawanyawisuth $\mathrm{K}$, Mahakkanukrauha A, Wongvipaporn C. Clinical Manifestations of Primary Hyperthyroidism in the Elderly Patients at the Out-Patient Clinic of Srinagarind Hospital. J Med Assoc Thai 2006; 89:178-181.

2. Shakaib UR, Jan NB, Florence NH. Diagnosis and Management of Hyperthyroidism in Older Adults. Geriatrics \& Aging 2006; 9:671-678.

3. Diez JJ. Goiter in adult patients aged 55 years and older: etiology and clinical features in 634 patients. J Gerontology 2005; 60:920-923.

4. Gordon $\mathrm{M}$, Isenberg $\mathrm{Y}$, Bain J. Unmasking Hyperthyroidism in the Elderly. Can Fam Physician 1992; 38:2397-2404.

5. Bagchi N, Brown TR, Parish RF. Thyroid Dysfunction in Adults over Age 55 Years. A Study in an Urban US Community. Arch Intern Med 1990; 150:785-787.

6. Mintzer MJ, Cattan R. Hypothyroidism and Hyperthyroidism in the Elderly. J Am GeriatrSoc 1986; 34:887-892.

7. Aronow WS. The Heart and Thyroid Disease. Clinics in Geriatrics Med 1995; 11:219-229.

8. Rozendaal FP. Hyperthyroidism in the Elderly: Aspecific sign may Cause a Delay in Diagnosis. TijdschrGerontolGeriatr2005; 36(2):77-80. [Dutch]

9. Vijaya MD, Abdullah S, Bret AL, Donal FK. An Uncommon Presentation of a Common Diagnosis: Nausea and Abdominal Pain in Thyrotoxicosis. Gastroenterol Hepatol 2009; 5:209-213. 